\title{
THE ROLE OF PROPRIOCEPTION IN THE HUMAN MOTION MECHANISM AND ITS RECOVERY AFTER RUPTURE OF THE ANTERIOR CRUCIATE LIGAMENT AND MENISCUS OF THE KNEE JOINT
}

\author{
Fedulova D.V.', Berdyugin K.A.,3 \\ ${ }^{1}$ Ural Federal University named after the first President of Russia B.N. Yeltsin, Ekaterinburg, e-mail: darya- \\ fedulova@yandex.ru; \\ ${ }^{2}$ Ural Institute of traumatology and orthopedics named after V.D. Chaklin, Ekaterinburg, e-mail: \\ kiralber73@rambler.ru; \\ ${ }^{3}$ Ural State Medical University, Ekaterinburg
}

Aims.

The aim of the study is to identify the degree of impairment and further recovery of proprioception after combined injury and rupture of the anterior cruciate ligament and meniscus of the knee joint.

Materials and methods.

A total of 75 athletes with a combined injury of the anterior cruciate ligament and meniscus were examined; they were aged 20 to 35 years and had no previous knee injuries. The average period from the time of injury to surgery was $2.5 \pm 0.5$ years. Standard methods of examination, treatment and rehabilitation were supplemented by balance training that was carried out from week 5 after surgery (static balance exercises from week 5 and dynamic balance exercises from week 9) on a firm and unstable support, as well as with optional sports equipment. Active and passive abduction of the extremity for different flexion angles of the knee and with the task to reproduce the abduction position was used as an evaluation test.

Results.

The study results showed that the proprioception after combined injury of the anterior cruciate ligament and meniscus of the knee joint has worse indicators on the injured extremity, i.e., the unilateral influence of trauma on the state of motion sensitivity, but these indicators significantly improve with targeted balance training, and imbalance between the extremities becomes minimal.

Conclusions.

The position reproduction test (the study of the accuracy of extremity bending to a certain angle) is a reliable rehabilitation effectiveness criterion in athletes with a combined injury of the anterior cruciate ligament and meniscus.

Keywords: proprioception, motion sensitivity, knee, recovery of ACL, physical rehabilitation, afferent connections.

INTRODUCTION. British physiologist Charles Bell (1774-1842) was the first to state that the muscular system was not simply an effector system, but also a sense organ of a kind; he thus laid the foundations of scientific knowledge of physiology behind motor actions. It is the bilateral (afferent and efferent) neural connection between the brain and the muscles that creates a closed circle, in which centrifugal pulses trigger muscular motion while muscle-generated centripetal pulses inform the brain on the current state of effectors and enable precision control over movements. Coordinated motor action is impossible without such muscular feedback.

In Russia, research into that problem was pioneered by Sechenov (1829-1905), who dubbed the proprioception "a dark sense", and continued by Bernstein (1896-1966), whose ideas of a multilevel motor coordination system and reflex arcs are fundamental to today's ideas of movement coordination.

Like Bell, Bernstein believed that to enact this or that movement, the brain should not only send commands to muscles but also receive feedback from peripheral sense organs; the feedback provides information on what has been done and is used to issue adjustment controls. To prove his theory, Bernstein created the reflex arc chart and formulated the concept of activity physiology. 
However, if there are any disruptions in the afferent (organ-to-CNS) or efferent (CNS-toorgan) pathways, the motor action will be incomplete or inadequate.

In particular, proprioceptors, enabling data exchange, were discovered in the knee in 1980. It was found out that up to $50 \%$ of such proprioceptors were located in the anterior cruciate ligament [1], a rupture of which would alter the afferent signaling in the reflex arc.

Proprioception is the ability to perceive position and spatial motion of one's own body or its individual segments [2]. Given that this process involves motor analyzers, the authors herein propose the term "motor sensitivity" as an alternative to "proprioception".

This study relies upon the controversial data on the mechanism and degree of proprioception recovery after ACL or knee meniscus injury:

1. Some researchers believe that ACL injuries only affect proprioception and body balance on the side of the injured limb [3;4], while others suggest and prove that each such injury has a bilateral effect, i.e. ligament injury to only one knee will affect proprioception in both [5; 6].

2. Contrary to researchers' popular opinion that proprioception will not recover by itself, there is evidence that post-traumatic proprioception recovery does occur regardless of whether any action is taken to help recover it [7]; there is also evidence that operated and nonoperated knees do not differ in the sensory function [8;9].

The goal hereof was to identify the extent, to which a combined injury (ACL rupture and knee meniscus rupture) affects proprioception, as well as the extent, to which it may recover.

MATERIALS AND METHODS. Research was carried out at the Ural Institute of Traumatology and Orthopedics named after V.D. Chaklin, as well as at the Institute of Physical Education, Sports, and Youth Policy, Ural Federal University named after the first President of Russia B.N. Yeltsin.

It involved 75 persons aged 20 to 35, having experienced a combined ACL end meniscus injury with no prior knee injury. Experiment participants were mainly adult Class 1 or Class 2 athletes who had been injured while doing sports: $71 \%$ were engaged in team sports (mostly football), $25 \%$ in martial arts, and $4 \%$ in other sports. On average, the injury-to-surgery period was $2.5 \pm 0.5$ years.

The study protocol followed guidelines for experimental investigation with human subjects in accordance with the Declaration of Helsinki and was approved by the ethics committee. Written informed consent was obtained from each patient (or official representative) before the study.

The participants were split into two groups: the experimental group (38 persons, 15 girls and 23 boys) and the control group (37 persons, 15 girls and 22 boys). In the experimental group, 22 athletes had a left knee injury (58\%) and 16 had a right-knee injury (42\%). In the control group, 20 athletes had a left-knee injury (54\%) and 17 had a right-knee injury (46\%). The groups were composed to be homogeneous in terms of how these people had been injured. Beside the primary injury (ACL rupture), all the patients had a meniscus injury (medial meniscus injury in $67 \%$ and lateral meniscus injury in $33 \%$ ). 
The control-group athletes were undergoing a physical rehabilitation program offered by the Ural Institute of Traumatology and Orthopedics named after V.D. Chaklin (UITO), while the experimental-group athletes were undergoing a special physical rehabilitation program developed by the authors hereof specifically to help recover from this type of injury.

Experiment participants underwent 14-day treatment at the UITO hospital, where they had ACL restoration surgery using an autotransplant from hamstrings (semitendinosus muscle and gracilis muscle tendons) coupled with partial or total meniscus removal. After discharge, the athletes were offered 6-month physical rehabilitation programs at the facility: exercise therapy twice a week, then hydrokinesitherapy once a week starting from Week 8.

Position reproduction tests were used to assess how far the proprioception was affected and recovered; the test task was to reproduce a specific knee flexion angle. First, an athlete had his or her limb flexed at $30^{\circ}$ and $60^{\circ}$. The task was to repeat flexion at the same angles on their own. The test was conducted separately with eyes open and shut. The research team estimated the difference between the original angle and the athlete-attained angle. The test was done 5 times over the rehabilitation period: once before surgery, then 7 weeks, 3 months, 4.5 months, and 6 months after surgery.

RESULTS. As part of this study, the research team analyzed 35 Russian and 35 international papers to identify the most common methods for assessing the post-CL reconstruction recovery so as to find out what role this study and post-traumatic proprioception recovery assessment would play in the general rehabilitation algorithm. The results of that overview were published in [10]. This paper dwells specifically upon proprioception.

Thirty $(43 \%)$ papers in the analyzed collection described loosening, 37 (53\%) dwelt upon the condition of circumarticular muscles, and 13 (19\%) covered proprioception within the framework of assessing recovery from CL rupture. Thus, post-traumatic proprioception was the least studied topic.

A patient's proprioception capacity is mainly assessed by instrumental methods: stabilometry and motion analysis. Stabilometry is mainly used in Russia while motion analysis is preferred internationally.

In addition to instrumental tests, the motor analyzer can be assessed by basic techniques, i.e. by estimating how accurately a person can flex their limb to a specific angle, what force they can apply to a manual dynamometer while the eyes are shut, etc. Deviation from the specified value (in $\%$ ) was taken into account in all cases; the acceptable limit was $10 \%$ to $20 \%$. The accuracy of movements or force applied correlates directly to an athlete's training [11].

This research used the position reproduction test. Rehabilitation programs made emphasis on equilibrium training to restore the proprioceptive sensitivity and to attain symmetry in both limbs.

Equilibrium training was a set of exercises designed to develop the sense of equilibrium, to improve coordination and motor sensitivity; these exercises used unstable positions on the floor, on 
a yoga ball, on suspended systems, on unstable supports. The program was intended to trigger the nervous system, active and passive stabilizers and receptors.

To that end, special body equilibrium, static and dynamic stability exercises were performed during hydrokinesitherapy and exercise therapy. Static equilibrium exercises began during Week 5. After mastering the stationary-support exercises, the athletes started to use balance pads; starting from Week 9, they also did dynamic equilibrium exercises.

The table below summarizes how their motor sensitivity changed.

Position reproduction test results (degrees)

\begin{tabular}{|c|c|c|c|c|c|c|c|c|}
\hline \multirow[b]{2}{*}{ 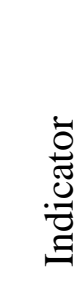 } & \multirow[b]{2}{*}{ ఏ్ } & \multirow[b]{2}{*}{ 芯 } & \multirow[b]{2}{*}{ 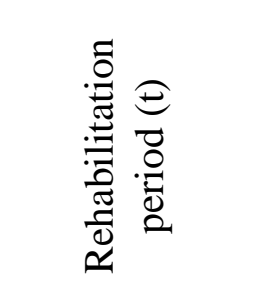 } & \multicolumn{5}{|c|}{ Statistical parameters } \\
\hline & & & & $\begin{array}{l}\mathrm{X} \\
\pm \\
\mathrm{m}\end{array}$ & $\mathrm{V}(\%)$ & $\Delta \mathrm{M}(\%)$ & $\begin{array}{l}\text { Intra- } \\
\text { group } \\
\text { P }\end{array}$ & $\begin{array}{l}\text { Inter } \\
- \\
\text { grou } \\
\text { p P }\end{array}$ \\
\hline \multirow{14}{*}{ 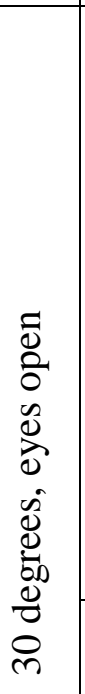 } & \multirow{12}{*}{$\begin{array}{l}\text { Non- } \\
\text { operated } \\
\text { limb }\end{array}$} & \multirow{6}{*}{ EXP. } & Before surgery & $6.33 \pm 0.67$ & 35.82 & & & \\
\hline & & & 7 weeks & $6.09 \pm 1.2$ & 30.65 & -3.2 & 0.791 & \\
\hline & & & 3 months & $5.25 \pm 0.96$ & 31.14 & -13.1 & 0.399 & \\
\hline & & & 4.5 months & $5 \pm 0.84$ & 34.11 & $\begin{array}{l}-5.7 \\
\end{array}$ & 0.803 & \\
\hline & & & 6 months & $3.09 \pm 0.6$ & 28.2 & -38 & 0.054 & \\
\hline & & & & & & -50.8 & $<0.001$ & \\
\hline & & \multirow{6}{*}{ CTRL } & Before surgery & $6 \pm 0.47$ & 33.57 & & & $>0.05$ \\
\hline & & & 7 weeks & $6.45 \pm 0.82$ & 39.35 & 8.3 & 0.639 & \\
\hline & & & 3 months & $6.08 \pm 0.7$ & 39.93 & -6.1 & 0.735 & \\
\hline & & & 4.5 months & $6.2 \pm 0.93$ & 41.03 & 1.6 & 0.934 & \\
\hline & & & 6 months & $5.7 \pm 0.82$ & 37.55 & -8.1 & 0.718 & \\
\hline & & & & & & -5 & 0.777 & 0.011 \\
\hline & \multirow[b]{2}{*}{$\begin{array}{l}\text { Operated } \\
\text { limb }\end{array}$} & \multirow{2}{*}{ EXP. } & Before surgery & $11.33 \pm 0.62$ & 17.3 & & & \\
\hline & & & 7 weeks & $12.63 \pm 0.88$ & 21.83 & 11.5 & 0.263 & \\
\hline
\end{tabular}




\begin{tabular}{|c|c|c|c|c|c|c|c|c|}
\hline & & & 3 months & $7.91 \pm 0.94$ & 29.15 & -37.3 & 0.001 & \\
\hline & & & 4.5 months & $6.18 \pm 1$ & 19.1 & -21.5 & 0.081 & \\
\hline & & & 6 months & $4 \pm 0.67$ & 13.07 & -35.5 & 0.008 & \\
\hline & & & & & & -64.6 & $<0.001$ & \\
\hline & & & Before surgery & $11.89 \pm 0.68$ & 17.05 & & & $>0.05$ \\
\hline & & & 7 weeks & $13.36 \pm 0.84$ & 20.97 & 12.6 & 0.19 & \\
\hline & & CTPI & 3 months & $11.25 \pm 0.55$ & 17 & -15.7 & 0.051 & \\
\hline & & CIRL & 4.5 months & $10.27 \pm 0.69$ & 15.82 & -8.8 & 0.281 & \\
\hline & & & 6 months & $10 \pm 0.79$ & 15.1 & -2.9 & 0.797 & \\
\hline & & & & & & -16 & 0.085 & $<0.001$ \\
\hline & & & Before surgery & $10.11 \pm 0.97$ & 35.14 & & & \\
\hline & & & 7 weeks & $9.54 \pm 1.12$ & 31.1 & -5.9 & 0.671 & \\
\hline & & & 3 months & $6.83 \pm 0.84$ & 42.76 & -28.4 & 0.031 & \\
\hline & & EXP. & 4.5 months & $6.18 \pm 0.69$ & -38.19 & -10.3 & 0.477 & \\
\hline & & & 6 months & $3.81 \pm 0.67$ & 39.08 & -37.7 & 0.01 & \\
\hline & & & & & & -62.4 & $<0.001$ & \\
\hline & Non- & & Before surgery & $9.67 \pm 1.58$ & 33.52 & & & $>0.05$ \\
\hline & limb & & 7 weeks & $9.64 \pm 1.93$ & 31.91 & -1 & 0.983 & \\
\hline & & & 3 months & $8.42 \pm 1.04$ & 43.71 & -12.5 & 0.397 & \\
\hline & & CTRL & 4.5 months & $7.54 \pm 0.97$ & 39.84 & -10.7 & 0.465 & \\
\hline & & & 6 months & $7.91 \pm 0.84$ & 35.44 & 5.3 & 0.767 & \\
\hline Е & & & & & & -18.6 & 0.271 & 0.005 \\
\hline$n$ & & & Before surgery & $14.41 \pm 1.12$ & 27.12 & & & \\
\hline خे & & & 7 weeks & $14.27 \pm 1.08$ & 25.16 & -1.4 & 0.815 & \\
\hline$\dot{s}$ & & EXP & 3 months & $9.36 \pm 0.95$ & 31.03 & -34.5 & $<0.001$ & \\
\hline 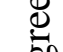 & & EXP. & 4.5 months & $7.49 \pm 0.82$ & 36.75 & -20.4 & 0.065 & \\
\hline 0 & & & 6 months & $4.45 \pm 0.9$ & 31.28 & -40.5 & 0.004 & \\
\hline m & & & & & & -69.4 & $<0.001$ & \\
\hline & Operated & & Before surgery & $13.7 \pm 0.84$ & 26.15 & & & $>0.05$ \\
\hline & & & 7 weeks & $14.36 \pm 0.43$ & 29.98 & 5.1 & 0.432 & \\
\hline & & & 3 months & $12.45 \pm 0.63$ & 24.07 & -13.2 & 0.011 & \\
\hline & & CTRL & 4.5 months & $11.8 \pm 0.57$ & 29.97 & -5.6 & 0.422 & \\
\hline & & & 6 months & $11.27 \pm 0.54$ & 26.61 & -4.2 & 0.683 & \\
\hline & & & & & & -17.5 & 0.095 & $<0.001$ \\
\hline & & & Before surgery & $4.89 \pm 0.73$ & 45.1 & & & \\
\hline & & & 7 weeks & $4.73 \pm 0.66$ & 46.43 & -4.1 & 0.872 & \\
\hline & & & 3 months & $3.58 \pm 0.81$ & 58.44 & -23.4 & 0.287 & \\
\hline & & EXP. & 4.5 months & $2.27 \pm 0.45$ & 55.53 & -36.1 & 0.176 & \\
\hline & & & 6 months & $1.45 \pm 0.25$ & 46.39 & -39.1 & 0.13 & \\
\hline & & & & & & -71.4 & 0.001 & \\
\hline & Non- & & Before surgery & $4.11 \pm 0.59$ & 42.9 & & & $>0.05$ \\
\hline ฉ్ & $\begin{array}{l}\text { operated } \\
\text { limb }\end{array}$ & & 7 weeks & $4.73 \pm 0.66$ & 46.43 & 14.6 & 0.495 & \\
\hline $\begin{array}{l}0 \\
n\end{array}$ & & CTR I & 3 months & $4.67 \pm 0.64$ & 47.77 & 0 & 0.948 & \\
\hline ટ્త & & CTRL & 4.5 months & $4.54 \pm 0.64$ & 46.53 & -4.2 & 0.895 & \\
\hline$\dot{s}$ & & & 6 months & $4 \pm 0.62$ & 51.23 & -11.1 & 0.546 & \\
\hline 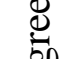 & & & & & & -2.4 & 0.898 & 0.002 \\
\hline 0 & & & Before surgery & $7.56 \pm 0.69$ & 27.37 & & & \\
\hline 8 & & EXP & 7 weeks & $9.64 \pm 0.82$ & 28.33 & 26.2 & 0.069 & \\
\hline & Operated & EXP. & 3 months & $5.92 \pm 0.97$ & 46.96 & -38.5 & 0.008 & \\
\hline & & & 4.5 months & $3.82 \pm 0.48$ & 41.93 & -35.6 & 0.071 & \\
\hline
\end{tabular}




\begin{tabular}{|c|c|c|c|c|c|c|c|c|}
\hline & & & 6 months & $2.09 \pm 0.41$ & 35.77 & -44.7 & 0.013 & \\
\hline & & & & & & -72.4 & $<0.001$ & \\
\hline & & & Before surgery & $7.44 \pm 0.72$ & 29.36 & & & $>0.05$ \\
\hline & & & 7 weeks & $8.27 \pm 0.52$ & 31 & 12.2 & 0.37 & \\
\hline & & & 3 months & $8.08 \pm 0.67$ & 28.63 & -2.4 & 0.826 & \\
\hline & & CIRL & 4.5 months & $7.09 \pm 1.05$ & 35.04 & -12.3 & 0.436 & \\
\hline & & & 6 months & $6.64 \pm 1.02$ & 32 & -7 & 0.759 & \\
\hline & & & & & & -10.8 & 0.528 & 0.001 \\
\hline & & & Before surgery & $5.22 \pm 0.15$ & 38.44 & & & \\
\hline & & & 7 weeks & $8 \pm 0.75$ & 31.12 & 53.8 & 0.004 & \\
\hline & & & 3 months & $5.17 \pm 0.59$ & 39.44 & -35 & 0.008 & \\
\hline & & EXP. & 4.5 months & $4.81 \pm 0.76$ & 42.36 & -7.7 & 0.72 & \\
\hline & & & 6 months & $3.18 \pm 0.44$ & 36.23 & -33.3 & 0.081 & \\
\hline & & & & & & -38.5 & $<0.001$ & \\
\hline & Non- & & Before surgery & $6 \pm 0.47$ & 33.57 & & & $>0.05$ \\
\hline & operated & & 7 weeks & $6.81 \pm 0.85$ & 41.39 & 13.3 & 0.413 & \\
\hline & & CTR I & 3 months & $6.25 \pm 0.68$ & 37.45 & -7.3 & 0.607 & \\
\hline & & CIKL & 4.5 months & $5.81 \pm 0.64$ & 36.71 & -7.9 & 0.648 & \\
\hline & & & 6 months & $5.27 \pm 0.84$ & 33.03 & -8.6 & 0.613 & \\
\hline 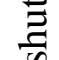 & & & & & & -11.7 & 0.463 & 0.044 \\
\hline $\begin{array}{l}\bar{n} \\
n \\
n\end{array}$ & & & Before surgery & $8.7 \pm 1.06$ & 38.71 & & & \\
\hline ટ્త & & & 7 weeks & $11.73 \pm 0.66$ & 18.72 & 34.5 & 0.029 & \\
\hline$\hat{j}$ & & & 3 months & $8.54 \pm 0.77$ & 29.77 & -27.3 & 0.005 & \\
\hline $\mathscr{J}_{0}$ & & EXP. & 4.5 months & $7.54 \pm 0.78$ & 34.23 & -11.8 & 0.371 & \\
\hline ర్ర & & & 6 months & $3.73 \pm 0.33$ & 29.61 & -50.7 & $<0.001$ & \\
\hline 8 & & & & & & -57.5 & $<0.001$ & \\
\hline & Uperated & & Before surgery & $8.6 \pm 1.06$ & 38.83 & & & $>0.05$ \\
\hline & & & 7 weeks & $10.73 \pm 0.85$ & 26.4 & 24.4 & 0.135 & \\
\hline & & & 3 months & $10.45 \pm 0.72$ & 22.78 & -2.8 & 0.809 & \\
\hline & & CTRL & 4.5 months & $9.09 \pm 0.88$ & 32.05 & -12.5 & 0.244 & \\
\hline & & & 6 months & $8.1 \pm 0.55$ & 22.42 & -11 & 0.348 & \\
\hline & & & & & & -5.8 & 0.675 & $<0.001$ \\
\hline
\end{tabular}

\section{CONCLUSIONS.}

1. Resolving controversial points and contradictions in the overviewed papers on proprioception recovery, it should be noted that proprioception is worse in the injured limb in cases of combined ACL+meniscus injury, which means that this injury affects motor sensitivity unilaterally. However, targeted equilibrium training improved these indicators significantly in the experimental group as compared to the controls, i.e. recovery and functional limb alignment are indeed possible.

2. Proprioception is mainly assessed by instrumental tests; however, the overview shows only $19 \%$ of researchers covered proprioception assessment in their rehabilitation programs. Most studies focus on improving muscular strength and joint stability.

\section{FINANCIAL SUPPORT AND SPONSORSHIP}

Nil. 


\section{SUPPLEMENTARY DATA (DOI)}

\section{REFERENCES}

1. Ferrell W.R. The adequacy of stretch receptors in the cat knee joint for signalling joint angle throughout a full range of movement. Journal of Physiology, 1980, vol. 299, no 1, pp. 85-99, doi 10.1113/jphysiol.1980.sp013112.

2. Larchenko N.A. Dictionary-directory of medical terms and basic medical concepts [Slovar'spravochnik meditsinskikh terminov i osnovnykh meditsinskikh poniatii], Rostov-on-Don, Feniks, 2013, 602 p.

3. Lee H.-M., Cheng C.-K., Liau J.-J. Correlation between proprioception, muscle strength, knee laxity, and dynamic standing balance in patients with chronic anterior cruciate ligament deficiency. The Knee, 2009, vol. 16, no 5, pp. 387-391, doi 10.1016/j.knee.2009.01.006.

4. Shim J.-K., Choi H.-S., Shin J.-H. Effects of neuromuscular training on knee joint stability after anterior cruciate ligament reconstruction. Journal of Physical Therapy Science, 2015, Vol. 27, no 12, pp. 3613-3617, doi 10.21203/rs.2.19922/v1.

5. Arockiaraj. J., Korula R.J., Oommen A.T. et al. Proprioceptive changes in the contralateral knee joint following anterior cruciate injury. The Bone and Joint Journal, 2013, vol. 95-B, no 2, pp. 188191, doi 10.1302/0301-620x.95b2.30566.

6. Lepley A.S., Ericksen H.M., Sohn D.H. et al. Contributions of neural excitability and voluntary activation to quadriceps muscle strength following anterior cruciate ligament reconstruction, The Knee, 2014, vol. 21, no 3, pp. 736-742, doi 10.1016/j.knee.2014.02.008.

7. Angoules A.G., Mavrogenis A.F., Dimitriou R. et al. Knee proprioception following ACL reconstruction; a prospective trial comparing hamstrings with bone-patellar tendon-bone autograft. The Knee, 2011, Vol. 18, no 2, pp. 76-82, doi 10.1016/j.knee.2010.01.009.

8. Cooper R.L., Taylor N.F., J.A. Feller N.F. A systematic review of the effect of proprioceptive and balance exercises on people with an injured or reconstructed anterior cruciate ligament. Research in Sports Medicine, 2005, Vol. 13, no 2, pp. 163-178, doi 10.1080/15438620590956197.

9. Akbari A., Ghiasi F., Mir M. et al. The effects of balance training on static and dynamic postural stability indices after acute ACL reconstruction. Global Journal of Health Science, 2016, vol. 8, no 4, pp. 68-81, doi 10.5539/gjhs.v8n4p68

10. Fedulova D.V., Iamaletdinova G.A. Methods of evaluation of the process of recovery after reconstruction of cruciate ligaments of knee joint [Metody otsenki protsessa vosstanovleniia posle rekonstruktsii krestoobraznykh sviazok kolennogo sustava]. Scientific and sports bulletin of Ural and Siberia - Nauchno-sportivnyi vestnik Urala i Sibiri, 2018, no. 1, pp. 68-86.

11. Ed. Karpman V.L. Sports medicine: textbook for institutes of physical culture [Sportivnaia meditsina: uchebnik dlia institutov fizicheskoi kul'tury]. Moscow, Fizkul'tura i sport, 1987, 304 p. 